\title{
O pequeno leitor e o processo de mediação de leitura literária'
}

\author{
The young reader and mediation process of literary reading
}

\author{
GREICE FERREIRA DA SILVA \\ DAGOBERTO BUIM ARENA \\ Universidade Estadual Paulista Júlio de Mesquita Filho - UNESP \\ Brasil \\ grebalet@terra.com.br \\ dagobertobuim@hotmail.com
}

Resumo. $O$ presente artigo busca discutir a formação literária desde a pequena infância, entendendo por pequena infância o período destinado à Educação Infantil que compreende as crianças de zero a cinco anos. Este trabalho objetiva fazer alguns apontamentos sobre o ensino e a aprendizagem da leitura, suas relações com a literatura infantil e a formação do gosto literário. Discute também o papel da mediação do professor, nesse processo de educação literária, e da escola como um espaço em que essa mediação deve ocorrer.

Palavras-chave: formação de leitores; leitura literária; educação infantil.
Abstract.This article discusses literary education from early childhood, understanding early childhood as the nursery period from zero to five years. This paper aims to make some observations about the teaching and learning of reading, their relationships with children's literature, and the formation of literary taste. It also discusses the mediating role of the teacher in the process of literary education, and the school as a space in which this mediation should occur.

Key words: education of readers; literary reading; infant education.

\footnotetext{
${ }^{\text {I }}$ Para citar este artículo: Da Silva, Greice Ferreira y Arena, Dagoberto Buim (20I2). O pequeno leitor e o processo de mediação de leitura literária. Alabe 6. [www.revistaalabe.com]

(Recibido o6-O2-2OI2; aceptado 2O-IO-2OI2)
} 


\section{Introdução}

Inserir-se na cultura escrita não é somente aprender a ler e a escrever: é também modificar a relação com a linguagem e com o mundo ao redor. Assim, é possível pensar que é na Educação Infantil que as crianças iniciam esse processo de inserção na cultura escrita, e é na escola da pequena infância que se deve pensar nos modos de se promover vivências para que essa inserção ocorra de forma necessária e adequada².

Este trabalho se propõe a pensar a literatura infantil como um meio de humanização das crianças desde a Educação Infantil e como um instrumento de inserção da criança na cultura escrita. Para tanto, num primeiro momento, serão feitas algumas considerações sobre o ensino da leitura e da literatura, para analisar como acontece nas escolas. E, num segundo momento, o leitor será convidado a refletir sobre o como a leitura literária pode mediar esse processo inicial de formação do pequeno leitor e da formação do gosto literário. Nessa trajetória, serão discutidos conceitos como humanização e cultura escrita, relacionados ao papel mediador do professor e da escola, no processo de apropriação da leitura e da literatura pelas crianças pequenas.

\section{A leitura e a literatura na escola}

No campo da leitura, desde r98o, destacam-se dois movimentos que se deram de forma lenta e gradativa, mas que de certa maneira atuam para a valorização da literatura infantil e o seu reconhecimento como um gênero discursivo: o abandono dos materiais impressos destinados especificamente ao ensinar e ao aprender a ler - os manuais, como as cartilhas etc. - e "a incorporação do livro de literatura infantil nas salas de aula, acompanhada pela rápida expansão de produção editorial de qualidade" (Arena, 2OIO: I3-I4). Esses movimentos contribuíram para que novas discussões surgissem acerca das relações entre literatura infantil, alfabetização e o ensinar e o aprender a ler. Uma dessas discussões está relacionada ao fato de o texto ser usado como pretexto no ensino e na aprendizagem da leitura (Lajolo, I986) ou, em outras palavras, a didatização ou pedagogização da literatura para crianças (Arena, 20IO: I4) que, de certo modo, já está superada no Brasil.

Por outro lado, quando se discute a literatura infantil na sala de aula, seus usos e suas implicações diretas no fazer pedagógico, há que se considerar ainda que, no processo de ensino da leitura, existe, muitas vezes, a utilização de materiais escolares, os quais apresentam textos descontextualizados, que priorizam o trabalho com letras ou sílabas e geralmente não causam interesse e envolvimento por parte da criança. Outrora eram priorizados pelos editores somente alguns gêneros discursivos, por se acreditar que eram mais adequados para a fase inicial da leitura. Ao fazer isso, descartava-se o emprego de outros gêneros que poderiam contribuir para a apropriação da leitura das crianças e

\footnotetext{
${ }^{2}$ Texto apresentado no I8 COLE (Congresso de leitura do Brasil) em i9 de julho de 20 2.
} 
aproximava-se a criança da concepção de leitura como uma tarefa eminentemente escolar. A esse respeito, Geraldi (2003) assinala que,

(...) se considerarmos as práticas normalmente propostas por livros didáticos, toda lição ou unidade destes livros, organizados em unidades e, em geral, sem unidade, iniciam-se por um texto para leitura. Como tais leituras não respondem a nenhum interesse mais imediato daqueles que sobre os textos se debruçam, a relação interlocutiva a ocorrer deverá se legitimar fora dela própria. Ou seja, mesmo quando a leitura se inspira em concepções mais interessantes sobre textos e sobre leitura, as relações interlocutivas a se empreenderem em sala de aula não respondem à necessidade do estabelecimento destas relações. Daí, sua legitimidade se estatuir e não se instituir. Os alunos, leitores e portanto interlocutores, lêem para atender a legitimação social da leitura externamente constituída fora do processo em que estão, eles, leitores/alunos, engajados. (Geraldi, 2003: I68-I69).

A leitura somente se institui na relação interlocutiva que pressupõe o dialogismo (Bakhtin, I992). Em outras palavras, ela se institui somente quando o leitor estabelece uma relação com o texto e com autor, numa atitude responsiva que o torna capaz de refutar, refletir e reavaliar o que leu. Do contrário, essa leitura não se constitui como tal, se fecha em si mesma, sem trazer uma contrapalavra (Bakhtin, I992). Ao considerar a concepção discursiva de Bakhtin, que pensa a língua em movimento, a língua que existe na relação com o outro, entende-se que somente desenvolver a competência linguística não responde aos objetivos da Educação Infantil e nem mesmo aos objetivos do ensino da literatura. A língua, nessa perspectiva, tem que ser vista nas relações sociais, nas trocas, na atitude responsiva.

Partilhando dessa ideia, Foucambert (I994: 3I) explicita:

Para aprender a ler, enfim é preciso estar envolvido pelos escritos os mais variados, encontrá-los, ser testemunha de e associar-se à utilização que os outros fazem deles - quer se trate dos textos da escola, do ambiente, da imprensa, dos documentários, das obras de ficção. Ou seja, é impossível tornar-se leitor sem essa contínua interação com um lugar onde as razões para ler são intensamente vividas (...).

Sobre o ensino e aprendizado da leitura, enfatiza:

Aprende-se a ler com textos, não com frases, menos ainda com palavras, jamais com sílabas (. . .), aprende-se a ler lendo textos que não se sabe ler, mas cuja leitura se tem necessidade. Lê-lo é procurar as respostas às perguntas que nos fazemos, as quais supomos estarem respondidas de alguma forma nos textos. Lê-los 
significa mobilizar tudo o que já sabemos, sobre a pergunta, sobre as possíveis respostas, sobre o funcionamento da escrita, para reduzir o espaço do que ainda é incompreensível. Ler - e, portanto, aprender a ler - é uma negociação entre o conhecido, que está na nossa cabeça, e o desconhecido, que está no papel; entre o que está atrás e o que está diante dos olhos. É um trabalho de detetive que utiliza índices (paginação, palavras conhecidas...) para elaborar hipóteses, verificálas com base em outros índices, voltar aos pontos que permanecem obscuros com ajudas externas. (Foucambert, 1994: 37-38).

Diante desses apontamentos, como pensar na literatura infantil desde a Educação Infantil? Como o professor da pequena infância pode mediar esse processo de inserção da criança na cultura escrita, por meio da literatura? Para tentar propor possíveis respostas a essas perguntas, inicialmente, é preciso esclarecer o que se entende por humanização e por cultura escrita, neste trabalho, com o intuito de se pensar a leitura e a literatura como objetos culturais, como meios de humanização das crianças. Para tanto, será oportuno recorrer à Teoria Histórico-Cultural preconizada por Vygotsky e seus colaboradores.

\section{A Teoria Histórico-Cultural eo ensino e a aprendizagem da leitura e da literatura}

A Teoria Histórico-Cultural, ou a chamada Escola de Vygotsky, enfatiza a natureza social do homem, o desenvolvimento da inteligência, da personalidade e da conduta humanas. Para essa teoria, o homem não nasce humano, mas aprende a sê-lo à medida que atua sobre a realidade e se apropria da cultura humana e a transforma; pode-se entendê-la como o conjunto da produção humana e da natureza que existe fora do homem, objetivamente, independente dele. É por meio da relação com os objetos socialmente criados e com os outros homens presentes e passados - e que deixam a marca de sua atividade nos objetos da cultura historicamente produzidos - que o homem se humaniza (Mello, I999).

Essa teoria vê o ser humano e a humanidade como produtos criados pelos homens, ao longo da história. Em outras palavras, ao criar a cultura humana - os objetos, os instrumentos, a ciência, a lógica, os valores, os costumes e hábitos, as linguagens - criam a própria humanidade, que é o conjunto das características e das qualidades humanas expressas pelas habilidades, capacidades e aptidões que foram se formando no decorrer da história, por meio da própria atividade humana. Essas aquisições não são herdadas biológica ou geneticamente, mas se fixam sob a forma de objetos externos da cultura material e intelectual. Nesse sentido, cada nova geração nasce num mundo pleno de objetos criados pelas gerações precedentes, e nesses objetos estão acumuladas as qualidades humanas histórica e socialmente criadas e desenvolvidas. É preciso que as novas gerações se apropriem desses objetos, de acordo com a função social para a qual foram criados (Mello, 2007). 
Conforme Vygotsky (1995), somente na relação social com os outros, mais avançados, é que as novas gerações internalizam e se apropriam das funções tipicamente humanas, como a fala, o pensamento, o controle da própria conduta, a função simbólica da consciência. Por essa concepção de homem, compreende-se que o processo de educação é essencialmente de humanização (Leontiev, r978). Por essa razão, o processo de educação é de formação das características e qualidades humanas e, assim, a escola deve ser o lugar de criação de novas necessidades humanizadoras, de garantia de experiências diversas às crianças, para que o desenvolvimento das máximas qualidades humanas se realize plenamente. Os estudos dessa teoria contribuem para redimensionar o conceito de educação e o conjunto de concepções que subsidiam as práticas educativas, principalmente na Educação Infantil e no que diz respeito à formação de crianças leitoras de literatura infantil.

Para Vygotsky, a criança nasce com uma única capacidade, a de criar capacidades. A infância é o período em que a criança entra na cultura humana e se apropria dela (Leontiev, I978; Mello, 2007; Vygotsky, I995). Com base nesses pressupostos, Britto (2005) entende que o termo cultura escrita, de forma mais ampla, procura caracterizar um modo de organização social cuja base é a escrita. Esse autor esclarece que cultura escrita implica valores, conhecimentos, modos de comportamento que não se limitam ao uso objetivo do escrito e, nesse sentido, representa a "relação da escrita com o desenvolvimento; a inter-relação escrita/oralidade; as demandas por habilidades cognitivas e o modo de produção atual” (Britto, 2005: I5). Assim, é possível pensar que é na Educação Infantil que as crianças devem iniciar esse processo de inserção na cultura escrita, devendo o professor, desde a escola da pequena infância, pensar nos modos de se promover vivências para que essa inserção ocorra de maneira necessária e adequada.

\section{Leitura e literatura: a formação do gosto literário}

De acordo com Arena (2003), lemos porque temos necessidades que são criadas pelas relações sociais entre os indivíduos; por tal razão, afirma que não lemos por hábito, gosto ou prazer. Nessa perspectiva, a escola tem o papel de criar essas necessidades de leitura nas crianças, permitindo que elas vivenciem situações reais em que possam participar dessas situações ativamente, sendo sujeitos de suas aprendizagens e percebendo a função social que a leitura ocupa na vida humana. Pode-se dizer que a educação literária se encontra nessas bases. Em outras palavras, a literatura deve fazer parte da vida da criança também na escola da pequena infância, de forma provocada, intencional, em que as situações de contato com a literatura sejam criadoras de novas necessidades de ler, de conhecer, de expressão e de se prazer por meio da relação dialógica que se estabelece com ela.

Diante desses apontamentos, vale ressaltar que o texto se constitui como tal no momento da relação do leitor com o texto, porque existe no momento em que se realiza, 
de sorte que, segundo Geraldi (I996: 80), “(. . .) o texto somente se completa com o ato de leitura ao ser utilizado, operado linguística e tematicamente pelo leitor”. A relação que o leitor vai manter com o texto está diretamente vinculada com a história de leitura de cada um. "A leitura é uma questão de natureza, de condições, de modos de relação, de trabalho, de produção de sentidos, em uma palavra: de historicidade” (Orlandi, I996: 9).

Nessa perspectiva, é possível pensar que o gosto literário está diretamente ligado às vivências de cada sujeito, às relações estabelecidas por ele, às condições concretas de vida e educação que cada um possui (Leontiev, I978), à sua própria história e a sua história de leitura. Em consonância com essas ideias, Geraldi (2003) esclarece:

O produto do trabalho de produção se oferece ao leitor, e nele se realiza a cada leitura, num processo dialógico cuja trama torna as pontas dos fios do bordado tecido para tecer sempre o mesmo e outro bordado, pois as mãos que agora tecem trazem e traçam outra história. Não são mãos amarradas - se o fossem, a leitura seria reconhecimento de sentidos e não produção de sentidos; não são mãos livres que produzem o seu bordado apenas com os fios que trazem nas veias de sua história - se o fossem, a leitura seria um outro bordado que se sobrepõe ao bordado que se lê, ocultando-o, apagando-o, substituindo-o. São mãos carregadas de fios que no que se disse pelas estratégias de dizer se oferece para a tecedura do mesmo e outro bordado. É o encontro destes fios que produz a cadeia de leituras construindo os sentidos de um texto. E como cadeia, os elos de ligação são aqueles fornecidos pelos fios das estratégias escolhidas pela experiência de produção do outro (o autor) com que o leitor se encontra na relação interlocutiva de leitura. A produção deste, leitor, é marcada pela experiência do outro, autor, tal como este, na produção do texto que se oferece à leitura, se marcou pelos leitores que, sempre, qualquer texto demanda. Se assim não fosse, não seria interlocução, encontro, mas passagem de palavras em paralelas, sem escuta, sem contrapalavras: reconhecimento ou desconhecimento, sem compreensão. (Geraldi, 2003: I66-I67).

Essas afirmações trazem o princípio dialógico da linguagem sob a ótica bakhtiniana e da leitura como um encontro dos interlocutores, marcado pela atitude responsiva do leitor que interage com o texto e com o autor, já pressupondo, no momento da leitura, uma contrapalavra. Essa dinamicidade interlocutiva possibilita que o leitor considere, critique, avalie, retome, desconsidere, debata o texto e, num contínuo processo de compreensão, responda às suas próprias perguntas e àquelas propostas pelo autor, que já tem dentro dele um leitor.

A concepção de leitura presente neste trabalho é a de leitura como compreensão, como produção de sentido e como prática cultural. Essa concepção vem ao encontro da concepção bakhtiniana de linguagem, que permite pensar a prática educativa, o ensino e a aprendizagem da leitura numa perspectiva dialógica, em que as relações travadas com 
o texto superam a mera decifração e oralização de sinais gráficos. A aprendizagem da criança na escola se apoia na leitura e pode-se dizer que isso é consenso, uma vez que é por meio dela que a criança terá contato e poderá conhecer os diferentes conteúdos escolares. Embora haja o reconhecimento espontâneo de que ler é entender um texto, a escola contradiz com certa frequência essa afirmação, ao sustentar o ensino da leitura em exercícios e tarefas que aparentam garantir o aprendizado da leitura pelas crianças, "mas que paradoxalmente, nunca é prioritário o desejo de que entendam o que diz o texto" (Colomer; Camps, I996: 29). A leitura é uma via de acesso para participar da cultura escrita, e, desse modo, ler se constitui numa necessidade essencial para garantir o pertencimento e a atuação ativa nessa sociedade.

Nessa perspectiva, a literatura deve aparecer no cenário escolar de sorte a contribuir na formação de leitores e não de "ledores". Perrotti (r999 apud Souza; Girotto, 2008: 66) distingue o ledor do leitor com a seguinte argumentação:

O ledor prefigura aquele ser passivo, imobilizado, que pouco ou nada acrescenta ao ato de ler. O texto para o ledor não tem aberturas porque ele decifra mecanicamente os seus sinais. Não há mistério, nem criação. A leitura é definitiva. O leitor, no entanto, é móvel e tem um olhar indefinido, errante e criativo sobre o texto, que se permite ler em suas linhas e entrelinhas, desvelando seus sinais visuais e invisíveis. Isto só ocorre quando se dá o pacto entre texto e leitor, que o ledor não se arrisca a fazer.

O enfoque dado ao aspecto físico do signo subsidia muitas práticas educativas, no início da aprendizagem da leitura. Pode-se inferir que a preocupação excessiva com a fonética e com a decodificação forma crianças ledoras e não leitoras. Em outras palavras, são crianças que apenas repetem ou pronunciam as palavras e frases que compõem um texto, mas que não conseguem compreendê-los e não participam dialogicamente do processo de significação da leitura pelas próprias condições educativas a que estão submetidas.

A literatura implica diálogo, interação com o texto, com a estética e, por isso, requer para si leitores e não ledores. A literatura exige do leitor uma interlocução, envolvimento, esforço para atuar no texto e com o texto, ao lidar intensamente com os enunciados que desvelam e revelam em si o conteúdo temático, o estilo e a construção composicional (Bakhtin, 2003, p. 26I). Esse esforço os ledores não dão conta de fazer. Nessa relação dialógica de leitor e texto literário, há também por parte do leitor a sua própria criação e a sua imaginação, as quais conferem e atribuem ao texto o sentido. Para Vygotsky (2009: I4),

(...) a imaginação, base de toda atividade criadora, manifesta-se, sem dúvida, em todos os campos da vida cultural, tornando possível a criação artística, a científica e a técnica. Nesse sentido, necessariamente, tudo o que nos cerca e foi feito 
pelas mãos do homem, todo o mundo da cultura, diferentemente do mundo da natureza, tudo isso é produto da imaginação e da criação humana que nela se baseia.

Arena (2OIO, p. 30), ao analisar as considerações de Vygotsky e a relação com a literatura, aponta:

A imaginação transcende a própria criação literária porque move o próprio desenvolvimento da cultura humana em todas as áreas. Dessa forma, imaginar é inventar, criar, romper com o já construído para encontrar o ainda desconhecido. Imaginar, portanto, não faz apenas parte do mundo infantil, mas é uma faculdade do homem, social e historicamente desenvolvida, necessária para a própria e permanente formação do ponto de vista filogenético.

O pequeno leitor imagina situações, ações, falas, baseado em suas experiências, no que já viu, ouviu, sentiu, percebeu, no que constitui a sua história, a sua vivência. O pequeno leitor imagina baseado naquilo de que já se apropriou e naquilo de que se apropria da cultura humana. Por isso, o leitor, ao lidar com os enunciados presentes na literatura, desenvolve sua imaginação e "quanto mais intensa for essa apropriação, mais imaginação desenvolverá” (Arena, 2OIO: 3I). Ao considerar esses pressupostos, é necessário entender que a criança, desde pequena, vive imersa numa sociedade do escrito e, por essa razão, Jolibert afirma que "ler é construir ativamente a compreensão de um texto, em função do projeto e das necessidades pessoais do momento, o que acontece a partir da educação infantil" (2006: I83).

As crianças são, desde pequenas, capazes de estabelecer relações com o escrito de forma a questioná-lo, de fazer previsões, escolhas, de validar essas antecipações ou não e assim elaborar outras questões e outras respostas. Pode-se dizer que a relação entre o leitor e o texto está imersa no mundo dialógico, ou seja, o leitor, no ato da leitura, traz os seus conhecimentos para dialogar com o texto, para compreendê-lo, e essa compreensão faculta a ele criar, modificar e elaborar novos conhecimentos.

Desse modo, pode-se inferir que a educação literária, o gosto pela leitura e pela literatura nascem de uma necessidade que é criada pelo professor, pelo contato com os leitores mais experientes e com as situações em que as crianças possam pôr em jogo suas ideias, sua imaginação, fazer previsões e antecipações e validá-las ou não. Lajolo (2005: II9), ao tratar do gosto literário, faz uma proposta de educação do gosto revelando que não cabe somente à escola essa função, mas que compete a ela a tarefa de iniciar seus alunos nos protocolos, nos critérios e nos valores da leitura.

Isto posto, cabe à escola cuidar para que as crianças tenham contato com os diferentes gêneros discursivos - no caso em questão, com o gênero literário - ao longo dos anos de escolaridade, a fim de que elas possam ampliar sua capacidade de manejar o mais possível a diversa heterogeneidade dos gêneros do discurso (orais e escritos), suas 
variações estilísticas e suas possibilidades de intervir e de dialogar com eles. Em decorrência, as crianças poderão se apropriar dos gêneros discursivos que circulam socialmente e se constituir gradativamente como leitores e como leitores literários, conforme as especificidades da literatura.

Neste tópico, buscou-se discutir a concepção de leitura para este trabalho e as implicações dessas concepções na educação literária e na formação do gosto literário. O tópico a seguir propõe-se a pensar sobre o papel mediador do professor e da escola, na educação literária das crianças.

\section{Educação literária: o professor e a escola como mediadores desse processo}

Percebem-se, nos dias atuais algumas iniciativas de professores e profissionais ligados à educação para a valorização da leitura e a preocupação em ampliar os tempos e os espaços para essa prática cultural. Intenta-se também diversificar as estratégias de leitura, para que a criança entre em contato com ela de forma lúdica e funcional. Inúmeros pesquisadores têm-se empenhado em mostrar aos pais e professores a importância da inclusão do livro no cotidiano da criança.

Comparada ao cinema, ao rádio e à televisão, a leitura tem vantagens únicas. Em vez de precisar escolher entre uma variedade limitada, posta à sua disposição por cortesia do patrocinador comercial, ou entre os filmes disponíveis no momento, o leitor pode escolher entre os melhores escritos do presente e do passado. Lê onde e quando mais lhe convém, no ritmo que mais lhe agrada, podendo retardar ou apressar a leitura; interrompê-la, reler ou parar para refletir, a seu bel-prazer. Lê o que, quando, onde e como bem entender. Essa flexibilidade garante o interesse contínuo pela leitura, tanto em relação à educação quanto ao entretenimento (....). (Harris, in Bamberger, I987: I3).

No processo de ensino e aprendizagem da leitura, as atividades devem ocorrer em situações reais, para que a criança possa atribuir um sentido adequado à sua função social. Mukhina (I996) e, posteriormente, Mello (r999) esclarecem que as condições pedagógicas ótimas para o desenvolvimento harmônico das crianças e das potencialidades não se apresentam por meio de um ensino imposto, forçado, com vista a transformar a criança pré-escolar em escolar prematuramente (Zaporózhets, I987).

A criança deve ser provocada para a leitura. Quando convive com a leitura e a escrita, a princípio realizadas pelo professor, enquanto vive muitas experiências significativas em que possa se expressar através das diferentes linguagens, ela se apropria da leitura e da escrita de forma "natural”, ou seja, não imposta, mecânica, ou mesmo espontaneamente como algo biológico, mas provocada (Mello, 2005). 
Ao relacionar o ensino e a aprendizagem da leitura com a literatura, faz-se necessário compreender o conceito de educação literária. Para Blanca (20o6, s.p.),

Entende-se por educação literária a adoção de uma metodologia que vai dotar o mediador com um conjunto de saberes culturais, literários, sociais, que fornecem as enciclopédias e os intertextos individuais, que permitem descobrir modelos, pautas, convencionalismos, símbolos, mitos, acontecimentos históricos..., uma reação individual perante uma obra literária. (Blanca, 2006: s.p.).

Nessa perspectiva, pode-se depreender que a educação literária se dá por ações específicas e metodologias apropriadas. O professor medeia esse processo de formação do leitor literário, quando planeja situações de leitura em que a criança entra em contato com o texto literário e com suas peculiaridades estéticas, linguísticas, artísticas, de modo que aprenda a dialogar com o texto, valorizar e ativar seus intertextos - outros e diversos textos que já conhece - e assim, produzir sentido. Isso ocorre porque o sentido atribuído ao texto também decorre da intertextualidade presente nele. As crianças se apoiam nos textos que conhecem e de que já fizeram repetidas leituras e, dessa maneira, os relacionam com as características do texto que é apresentado a elas. É por essa razão que "a intertextualidade na obra de Bakhtin é, antes de tudo, a intertextualidade "interna" das vozes que falam e polemizam no texto, nele reproduzindo o diálogo com os outros textos" (Barros, 2003: 4).

No processo de formação de leitores literários, o professor deve se apropriar de elementos que corroboram e são indispensáveis para esse processo de inserção da criança na cultura escrita. Tais elementos se referem às características peculiares do próprio gênero discursivo - no caso, o gênero literário - no que diz respeito ao conteúdo temático, estilo e construção composicional (Bakhtin, 2003). Por tal razão, o autor destaca:

Quanto mais dominamos os gêneros tanto mais livremente os empregamos, tanto mais plena e nitidamente descobrimos neles a nossa individualidade (onde isso é possível e necessário), refletimos de modo mais flexível e sutil a situação singular da comunicação; em suma, realizamos de modo mais acabado o nosso livre projeto de discurso. (. . .) Os gêneros do discurso, comparados às formas da língua, são bem mais mutáveis, flexíveis e plásticos; entretanto, para o indivíduo falante eles têm significado normativo, não são criados por ele mas dados a ele. Por isso um enunciado singular, a despeito de toda a sua individualidade e do caráter criativo, de forma alguma pode ser considerado uma combinação absolutamente livre de formas da língua (...). (Bakhtin, 2003: 285).

Aleitura, por mobilizar o conceito de gênero, coloca em ação modelos estruturais, temáticos e estilísticos relativamente fixos (contos, fábulas, crônicas de viagens, histórias policiais, poema épico etc.) que funcionam como formas mais ou menos estabilizadas e, 
portanto, reconhecíveis.

Dessa maneira, quando o professor domina as especificidades dos gêneros e, no caso do gênero literário, pode selecionar as obras literárias, os autores e as estratégias de leitura necessárias e adequadas para que as crianças sejam iniciadas no processo de apropriação do gênero literário. Cabe à escola e ao professor cuidarem para que as crianças tenham contato com os diferentes gêneros discursivos, durante os anos de escolaridade e ampliem sua capacidade de manejar o mais possível a diversa heterogeneidade dos gêneros do discurso (orais e escritos), suas variações estilísticas e suas possibilidades de intervir e de dialogar com eles. Assim, as crianças poderão se apropriar dos gêneros discursivos que circulam socialmente e se constituir gradativamente como leitores e como leitores literários.

A formação do leitor literário se funda nessa perspectiva, ou seja, quanto mais contato e diálogo o pequeno leitor tem com a literatura - entendendo-a como gênero discursivo - mais domínio o leitor terá sobre ela e poderá empregá-la mais livremente em situações concretas de comunicação, realizar "de modo mais acabado" o seu livre projeto de discurso (Bakhtin, 2003, p.I5) e garantir o seu ingresso e participação ativa na cultura escrita.

Por tudo isso, observa-se que a dimensão do dialógico, capaz de envolver as relações sociais, o espaço social e as matrizes geradoras de educação, é discutida nesse trabalho de ensino e aprendizagem da leitura e da literatura, por considerar o contexto em que esse processo se dá e como se dá. Para Bakhtin, não existe uma realidade de linguagem fora do dialógico e, em consequência, não existe uma realidade de leitura fora dessa dimensão. Nessa perspectiva, o ensino da língua, da leitura e da literatura só ocorre se ela for considerada, ou seja, se for levado em conta o processo interativo da linguagem, as trocas linguísticas dinâmicas entre as pessoas e os valores próprios de sua cultura, da sua historicidade. Isto posto, é possível argumentar:

A literatura deve fazer pensar, questionar, compreender e interrogar e, depois de nos exigir algum esforço, nos fazer sair dela diferentes, transformados de alguma forma. E para nos transformar, deve nos atrair, viver dentro de nós. Gianni Rodari, no belíssimo A Gramática da fantasia, assinala: “Todos os usos da palavra a todos, parece um bom lema, sonoramente democrático. Não exatamente porque todos sejam artistas, mas porque ninguém é escravo”. (I982, p. I8). O que vem corroborar nossa tese sobre a necessidade de leitura de bons livros e textos. (Souza; Girotto, 2008: 69).

Ao considerar esses pressupostos é que pensamos que a educação literária deve ser iniciada desde a Educação Infantil, e que os professores devem também se apropriar da literatura para poder dispor de meios mais adequados no processo de ensino e de aprendizagem e, por isso mesmo, poder fazer dela um instrumento humanizador, um instrumento da cultura. 


\section{Conclusão}

Na tentativa de discutir a formação do pequeno leitor e do pequeno leitor literário, buscou-se, neste trabalho, repensar aspectos do processo de ensino e de aprendizagem da leitura e da atuação da escola e do professor nesse processo.

Desde a Educação Infantil, crianças ainda não alfabetizadas convencionalmente podem estabelecer relações com o escrito, atribuindo significado e sentido, de modo que essas relações possam desenvolver condutas de leitor e criar nas crianças as necessidades de leitura. Ao perceber como essas relações se dão e ao compreender o processo de mediação da leitura literária, é possível refletir sobre as implicações pedagógicas no processo de ensino e aprendizagem da leitura e da literatura das crianças, nessa etapa da escolaridade, e reconhecer a necessidade da promoção de um trabalho pedagógico intencional de leitura com os diferentes gêneros discursivos e, portanto, do gênero literário.

Conforme pressupostos da Teoria Histórico-Cultural preconizada por Vygotsky (1995) e outros estudiosos, a aprendizagem é a fonte do desenvolvimento. Percebe-se que a criança desde pequena é capaz de estabelecer relações com o mundo que a cerca, de aprender, de imaginar de criar. Por tal motivo, a infância é um dos períodos mais importantes da vida humana, porque deve formar as bases orientadoras para novas aprendizagens. Se a escola e os professores compreenderem o papel essencial do processo educativo no processo de humanização e compreenderem como se dá o processo de aprendizagem, poderão organizar vivências na Educação Infantil que sejam intencionalmente provocadoras da aprendizagem e do desenvolvimento das crianças pequenas.

A formação do gosto literário desde a pequena infância ocorre pelas vivências que a criança tem, pelas relações que estabelece com o escrito, pela sua história de leitura que é tecida por tais vivências. Nesse processo de formação leitora, por meio da leitura literária, é fundamental que a escola - lugar em que as situações de leitura supostamente acontecem de forma mais sistematizada e frequente - promova situações de leitura, desafie os alunos a debater o texto, a construí-lo e a desconstruí-lo, instigue as crianças a ter um comportamento ativo, vigilante, de construção inteligente de significação (Charmeux, I997), e coloque as crianças em interlocução com o estilo, a temática e a construção composicional do gênero literário.

A formação do pequeno leitor e do leitor literário, sob uma perspectiva humanizadora, reside num processo pedagógico dialógico, porque, se o dialógico está na base de todas as relações do homem com o homem, com o mundo, com as coisas, com o conhecimento, também deveria estar no ensino e na aprendizagem das crianças e no processo de apropriação da leitura. Pode-se afirmar que esse processo é resultado de relações, de linguagens, de vozes, de relações polifônicas. A literatura, nesse cenário, se constitui como uma interlocutora da aprendizagem da leitura na Educação Infantil. 


\section{Referências Bibliográficas}

- Arena, D. B. (2003). Nem hábito, nem gosto, nem prazer. In: M. R. L. Mortatti (Org.). Atuação de professores: propostas para a ação reflexiva no ensino fundamental. (pp. 53-6I). Araraquara: JM.

- Arena, D. B. (2OIO). A literatura infantil como produção cultural e como instrumento de iniciação da criança no mundo da cultura escrita. In: R. J. Souza e et al. Ler e Compreender: Estratégias de leitura. (pp. I3-44). Campinas, SP: Mercado de Letras.

- Bakhtin, M. (1992). Marxismo e filosofia da linguagem. (5a. ed). Michel Lahud e Yara Frateschi Vieira, trad. São Paulo: Hucitec.

- Bakhtin, M. (2003). Estética da criação verbal. São Paulo: Martins Fontes.

- Bamberger, R. (1987). Como incentivar o hábito da leitura. São Paulo: Ática.

- Barros, D. L. P.; Fiorin, J. L. (Orgs.). (2003). Dialogismo, polifonia, intertextualidade: em torno de Bakhtin. (2a. ed.) São Paulo: Editora da Universidade de São Paulo.

- Blanca, A. R. R. (2006). Educación literaria e historias literarias. CAL - Conferéncias no Alentejo de Literatura Infanto - Juvenil- Texto inédito.

- Britto, L. P. L. (2005). Letramento e Alfabetização: Implicações para a Educação Infantil. In: A. L. G. Faria e S. A. Mello (Orgs.). O mundo da escrita no universo da pequena infância. (pp. 5-2I). Campinas, SP: Autores Associados. (Coleção Polêmicas do nosso tempo, 93).

- Charmeux, E. (1997). Aprender a ler: vencendo o fracasso. Maria José do Amaral Ferreira, Trad. (4a. ed.) São Paulo: Cortez.

- Colomer, T.; Camps, A. (2002). Ensinar a ler ensinar a compreender. Porto Alegre: Artmed.

- Foucambert, J. (1994). A leitura em questão. Porto Alegre: Artes Médicas.

- Geraldi, J.W. (1996). Linguagem e ensino: exercícios de militância e divulgação. Campinas: Mercado das Letras, I996.

- Geraldi, J.W. (2003). Portos de Passagem. São Paulo: Martins Fontes.

- Jolibert, J. (2006). Além dos muros da escola: a escrita como ponte entre alunos e comunidade. Ana Maria Netto Machado, Trad. Porto Alegre: Artmed. 
- Lajolo, M. (1986). O texto não é pretexto. In: R. Zilberman (Org.). Leitura em crise na escola: as alternativas do professor. (pp. 5-62). (7a. ed.) Porto Alegre: Mercado Aberto, I986.

- Lajolo, M. (2005). Do mundo da escrita para o mundo da leitura. São Paulo: Ática.

- Leontiev, A. N. (1978). O desenvolvimento do psiquismo. Lisboa: Livros Horizonte.

- Mello, S.A. (I999). Algumas Implicações Pedagógicas da Escola de Vygotsky para a Educação Infantil. Pro-Posições, Campinas, v.ıo, n.I, I6 - 27.

- Mello, S.A. (2005). O processo de aquisição da escrita na Educação Infantil - Contribuições de Vygotsky. In: A. L. G. Faria e S. A. Mello (Orgs). Linguagens Infantis - Outras formas de Leitura. (pp. 23-40). Campinas, SP. Autores Associados, 2005. (Coleção Polêmicas do nosso tempo, 9I).

- Mello, S.A. (2007). Infância e humanização: algumas considerações na perspectiva da teoria histórico-cultural. Perspectiva: Revista do Centro de Educação e Ciências Humanas. Florianópolis, v. 25, n. I, 83-IO4, jan/jun. 2007. Obtido em 20 de fevereiro de 2008 de http:// www.perspectiva.ufsc.br .

- Mukhina, V. (г996). Leis fundamentais do desenvolvimento psíquico. In: Psicologia da Idade Pré-escolar. (pp. 35-7o). Claudia Berliner, Trad. São Paulo: Martins Fontes.

- Orlandi, E. P. (r996). Discurso e leitura. (3a. ed.) São Paulo: Cortez; Campinas, SP: Editora da Universidade Estadual de Campinas. (Coleção Passando a limpo).

- Souza, R. J.; Girotto, C.G.G.S. (2008). Literatura infantil e juvenil: seleção de livros e textos, justificativas das escolhas sob o olhar do professor do Ensino fundamental. Letras de hoje, Porto Alegre, v. 43, n. 2, 64-70, abr./jun. 2008.

- Vygotsky, L. S. (1995). Obras Escogidas III. Madrid: Visor Distribuiciones.

- Vygotsky, L. S. (2009). Imaginação e criação na infância. São Paulo: Ática.

- Zaporózhets, A. (I987). Importancia de los períodos iniciales de la vida en la formación de la personalidad infantil. In: V. Davidov e M. Shuare, M. (Orgs.). La Psicología Evolutiva y Pedagógica em la URSS (Antologia). (pp. 228 - 249). Moscou: Editorial Progreso. 1987. 